\title{
A CULTURA ORGANIZACIONAL E SUA RELAÇÃO COM O DESEMPENHO DAS EMPRESAS
}

\author{
ORGANIZATIONAL CULTURE AND ITS RELATIONSHIP WITH THE \\ PERFORMANCE OF COMPANIE
}

\begin{abstract}
Milena Jesus de Souza
Acadêmica do $7^{\circ}$ período em Administração pela Alfa Unipac, Aimorés/MG, Brasil

E-mail: milenajs70@gmail.com
\end{abstract}

\section{Charleston Sperandio de Souza}

Mestre e Professor de Administração pela Alfa Unipac, Aimorés/MG, Brasil

E-mail: charleston.sperandio@yahoo.com.br

Recebido: 00/03/2020 - Aceito: 00/00/2020

\section{Resumo}

O presente artigo discursa sobre a relevância da cultura organizacional no âmbito das empresas e sabe-se que a cultura está presente em todos os ambientes da organização. O trabalho descreve as características da cultura organizacional e sua influência sobre o meio onde a mesma está estabelecida. $\mathrm{Na}$ administração, cultura organizacional é um dos maiores focos para entender as necessidades das pessoas envolvidas na organizacional, consequentemente, relacionar este processo com o resultado de metas almejadas. A pesquisa foi desenvolvida por caráter teóricoempírico, com o objetivo de contextualizar se a cultura organizacional e o comportamento da organização estão significativamente associados ao desempenho profissional, este artigo visa identificar as principais influências decorrentes das diferentes culturas dentro de uma organização, relacionadas à mudança de paradigmas que podem interferir no funcionamento dos processos e no desempenho dos trabalhadores, também abordou como realizar a avaliação dos funcionários na organização com as culturas distintas, e define-se que é necessário abordar o foco em determinadas dimensões coletivas da empresa, pois para analisar 0 comportamento é preciso apresentar feedbacks constantes e o desenho das etapas de trabalho. Assim, pode-se definir estratégias e planos de ação para administrar pessoas e equipes, melhorar o nível de desempenho, estimulando e despertando o interesse nos colaboradores, avaliando a subjetividade humana e minimizando os efeitos advindos desse processo.

Palavras chaves: Cultura organizacional; comportamento; paradigmas. 


\section{Abstract}

This article discusses the relevance of organizational culture within companies and knows that culture is present in all environments of the organization. The work describes characteristics of the organizational culture and its influence on the environment where it is defined. In administration, the organizational culture is one of the main focuses to understand the requirements of the people involved in the organization, consequently, relating this process to the result of desired goals. A research was developed by a theoretical-empirical character, with the objective of contextualizing whether the organizational culture and the organization's behavior are related to professional performance, this article aims to identify the main influences of different cultures within an organization, related to changing paradigms which can interfere with the functioning of processes and the performance of workers, also address how to carry out an assessment of employees in the organization with different cultures, and define whether it is necessary to address or focus on the use in focus of the collective displays of the company, to analyze behavior is I need to present constant feedbacks and the design of the work steps. Thus, you can define strategies and action plans to manage people and teams, improve the level of performance, stimulate and arouse the interest of employees, assess a human subjectivity and minimize the advanced effects of this process.

Keywords: Organizational culture; behavior; paradigms.

\section{Introdução}

A cultura organizacional permeia sobre os elementos do cotidiano da empresa, como hábitos, linguagem, metas e objetivos almejados do negócio, sendo assim, possuem influência sobre a essência dos membros de um ambiente, criando a personalidade de cada empresa. Toda organização, seja de médio ou grande porte, prestadora de bens ou serviços possui cultura organizacional, formalmente instituída ou não.

Segundo Barreto et al. (2013), a cultura organizacional está presente em diversos setores e níveis das organizações, atribuindo reconhecida influência sobre aspectos desde o comportamento de seus profissionais e gestores até a definição de estratégias e o desempenho organizacional.

Fleury e Fischer (1989) corroboram afirmando que a cultura é concebida como um conjunto de ideais e pressupostos básicos expressos em elementos simbólicos, que em sua capacidade de ordenar, atribuir significações, construir a 
identidade organizacional, tanto age como elemento de comunicação e consenso, como oculta e instrumentaliza as relações de dominação.

A relevância do tema se justifica por entender como a cultura dentro da organização impacta nos gestores, e como os mesmos compreendem a sua relação com o desempenho das organizações, pois as interações interpessoais são primordiais para o convívio social e profissional.

A fundamentação teórica da pesquisa tem uma revisão na literatura, encontrado nos autores, Hall,(1978), Fleury, Fischer(1989), Schein(1985), que trazem um apanhado histórico sobre cultura organizacional e o poder nas organizações, estruturas e processos organizacionais, cultura organizacional e liderança.

O presente artigo possui como objetivo explicar por meio da literatura a relação da cultura organizacional com o desempenho das empresas, que permeia em todos os setores organizacionais.

\subsection{Conceitos de Cultura Organizacional}

A cultura organizacional é considerada como uma rede de comportamentos complexos, contudo, pode ser definida como um grupo de mecanismos, controles, receitas, planos e instruções que comandam o comportamento (SILVA e ZANELLI, 2004).

Chiavenato (2004), explica que a cultura é como um iceberg, em que apenas $10 \%$ ou $20 \%$ ficam acima do nível da água, constituindo a parte visível. Grande parte permanece oculta, e as pessoas não conseguem enxergar. Seguindo a mesma perspectiva, a cultura organizacional apresenta aspectos formais, como as políticas, métodos, objetivos, estrutura organizacional e a tecnologia adotada. Entretanto, oculta alguns aspectos informais, sendo eles: percepções, sentimentos, atitudes, valores e as normas grupais. As questões mais ocultas da cultura organizacional são complexas para serem compreendidos e interpretados, como também de mudar ou sofrer transformações.

Na concepção de Schein (1984, p. 3), define-se:

Cultura organizacional é o padrão de premissas básicas que um grupo inventou, descobriu ou desenvolveu no processo de aprender a resolver seus problemas da adaptação externa e de integração interna e que funcionam suficientemente bem a ponto de ser considerada válida e, por 
isso, de ser ensinadas a novos membros do grupo como a maneira correta de perceber, pensar e sentir em relação a estes problemas.

Ferreira e Assmar (2004) definem que as empresas precisam encorajar seus funcionários a realizarem os objetivos estabelecidos pela empresa, pois desta forma, quanto mais disseminado os objetivos e a cultura estiverem conhecidos, mais possibilidades de ganho em relação ao lucro e melhora no desempenho serão alcançados ao longo do tempo,sendo que o compartilhamento de tais objetivos estará ao alcance de todos.

Segundo Chiavenato (2010), as empresas bem-sucedidas estão observando a importância de práticas gerenciais e culturas que privilegiem e preferem a participação dos funcionários, incentivando-os a terem valores e objetivos favoráveis a organização.

Robbins (2010) corrobora afirmando que a cultura organizacional transmitida aos funcionários por meio de diversas maneiras, sendo que as mais ponderadas são as histórias, que se referem a eventos ocorridos na empresa, quebras de regras, as estratégias da organização; rituais, expressam e reforçam os valores fundamentais da organização, ou seja, quais objetivos são mais importantes.

\subsection{Formas de Expressão da Cultura Organizacional}

De acordo com Lacombe (2003), a cultura pode ser definida em duas vertentes, explícita ou implícita, dependendo de cada empresa. A cultura explícita é transmitida por meio de códigos de ética, credos e por um conjunto das políticas e normas da organização, em relação a explícita, se torna a cultura oficial, sendo definida por meio de valores e ideais, nos quais podem coincidir (ou não) com o que é praticado. A cultura subtendida penetra de forma mais profunda do que palavras faladas e escritas.

Maximiano (2005) destaca que é por meio da socialização que os colaboradores aprendem e adquirem a cultura de uma organização. De maneira em que os recém-chegados são treinados a se comportar de acordo com as normas já existentes. O contrário muitas vezes também acontece. Os recém-chegados transmitem seus hábitos e valores aos integrantes do grupo que existia antes.

Fleury (1989) propõe que é possível distinguir três tipos de postura com referência à investigação dos fenômenos culturais das organizações. A primeira 
seria a empirista, ou do fotógrafo social, e implica considerar a sociedade como a somatória de indivíduos e a cultura como a somatória de opiniões e comportamentos individuais. A segunda seria a do antropólogo, em que o pesquisador penetra na vida organizacional como observador. A terceira seria do clínico ou terapeuta, que tem a organização como cliente ou objeto de estudo, e busca obter insights que auxiliarão na resolução de queixas por ela apresentadas.

Contudo, na concepção de Newstrom (2008) as culturas organizacionais têm em grande maioria como característica de serem relativamente estáveis. Desta forma essa característica é alterada de modo gradual, com eventos que ameacem a empresa.

Conforme Johann (2004), as características culturais da organização, por serem influenciadas pelos seus membros internos e externos, de certa forma pode possibilitar no seu interior, desenvolvendo subculturas. A descrição de subcultura é se define em relação a culturas diversificadas em existências simultâneas com seus valores.

Morgan (2009) enriquece o pensamento acima, na concepção de que, uma das maneiras de analisarmos a manifestação da subcultura é percebendo como os funcionários se comportam isto é, constatado quando fazemos parte da mesma e a entendemos de fora para dentro. As características se tornam desta maneira mais claras, como por exemplo, a maneira de falar, e de reagir com o colega de trabalho. Tais conjuntos são desenvolvidos quando conseguimos identificar as características próprias entre os departamentos da mesma.

\subsection{A Importância de Investigar a Cultura Organizacional}

De acordo com a concepção de Luz (2003), a cultura organizacional possui grande influência em relação a todos os membros que fazem parte da organização, desde a do operacional até aos cargos administrativos.

Pires e Macedo (2006) corroboram afirmando que, devido os funcionários participarem da cultura organizacional e social, os mesmos estão sobre a influência inevitável de ambas, a se atentar na forma como estes agem, pensam e se comunicam com os que estão em sua volta, pois é devido a essa interação entre as pessoas e o seu meio que irão se definir os objetivos a serem alcançados pela organização. 
Segundo Robbins (2005), o estudo da cultura organizacional faz-se importante, pelo fato em que permite aos gestores, em primeiro instante a visualização de como os valores da empresa estão sendo entendidos e em segundo, observar a diminuição do nível de resistência à mudança, facilitando desta forma aos mesmos, após a apresentação dos resultados, participarem de modo decisivo na execução dos planos de ações.

Complementando a concepção citada, Johann (2004), descreve que intervir sobre a cultura organizacional, além de identificar a absorção dos valores, viabiliza aos gestores atuarem de forma educativa e progressiva, instruindo sua equipe sobre as expectativas que a empresa possui sobre estes.

Para Luz (2003), analisar o clima organizacional é necessário, devido às diárias mudanças que as organizações estão sujeitas a passarem diariamente. $O$ entendimento do que vem a ser a estrutura do clima organizacional se faz por meio do reflexo do nível de satisfação ou de ânimo dos funcionários da organização, em um dado momento.

\subsection{Comportamento Organizacional e a Cultura Organizacional}

Segundo Glenn \& Malott (2004), a partir da visão da análise do comportamento, entende-se que a organização como a interação dinâmica entre o modo de agir dos gestores e seus produtos/realizações, e de acordo com as múltiplas tarefas desempenhadas por seus funcionários, haverá consequências individuais e outras consequências do acúmulo dos desempenhos estabelecidos, que por sua vez, podem ser entendidas como produto da organização, sendo assim, uma organização definida pelo que produz.

Redmon \& Wilk (1991), revelam que a preocupação com a aquisição do produto das organizações é uma das principais demandas sociais existentes nos dias de hoje, seja nas organizações públicas ou privadas.

$\mathrm{Na}$ visão de Cautilli \& Clarke (2000), para que uma organização possa viabilizar as condições, para que atinja os produtos almejados, que são de certa forma seus objetivos, são necessárias diversas formas de planejamento de estratégias para lidar com os indivíduos em interação.

Conforme a síntese de Cautilli, J. \&Clarke (2000), para que uma organização possa viabilizar as condições que dizem respeito a finalidade de atingir os produtos 
almejados, que de certa forma, são seus objetivos, são necessárias diversas formas de planejamento relacionado as estratégias para lidar com os indivíduos em interação.

Siqueira (2002), relata que a evolução das definições e conceituação do campo do comportamento relacionado a cultura organizacional, passa pela busca de tentar determinar os níveis de sua estrutura, as peculiaridades que as compõem, os temas de seu interesse $e$ as disciplinas que podem oferecer $o$ instrumental adequado para as análises e investigações.

$\mathrm{Na}$ visão de Mitchel (1979), para compreender o comportamento organizacional em relação a cultura da empresa, é necessário adotar-se um quadro de referência que abordava as dimensões relativas às dinâmicas psicossociais do indivíduo e as áreas de sua atuação no corpo organizacional.

Assim, as abordagens mais evidenciadas foram: personalidade, motivação, atitudes (satisfação, comprometimento, atribuições) e liderança.

Cummings (1982), apresenta um foco em áreas coletivas da organização, realizando abordagem em relação a tendência de evidenciar o campo a partir das produções que tem mais ênfase na organização como um todo, ressaltando a necessidade de avaliar a estrutura organizacional, políticas de recursos humanos, feedback, tecnologias, desenho do trabalho e contexto físico e controles.

Contudo, na perspectiva de Brief e Howard (2002), para avaliar o comportamento em relação a cultura organizacional objetiva-se avaliar as experiências afetivas, como humor e emoções em organizações de trabalho, apresentando um contexto histórico que valoriza questões sobre afeto no trabalho para observar a influência existente do afeto no ambiente de trabalho.

Por fim, Redmon \& Wilk (1991), relatam que se deve envolver a diversidade de aspectos relativos ao campo de estudo do comportamento organizacional. Faz-se necessário descrever as variáveis determinantes não só do comportamento individual, mas também de unidades coletivas, em especial da cultura organizacional.

\section{Metodologia}

A pesquisa teve caráter teórico-empírico, com o objetivo de estudar a Cultura Organizacional e sua relação com o desempenho das empresas, para isto optou-se 
por uma abordagem qualitativa. Considerando o objetivo proposto e o tema em questão, realiza uma investigação de natureza bibliográfica, descritiva básica, considerando que a mesma será composta de análises de referências teóricas (artigos, teses, livros.)

Morgan e Smircich (1980) definem que a pesquisa qualitativa é mais que um conjunto particular de técnicas; está implícita no modo de encarar o fenômeno social investigado.

Na compreensão de Vergara (2006), a pesquisa bibliográfica é o estudo sistematizado desenvolvido com base em materiais publicados em livros, revistas, jornais, redes eletrônicas, isto é material acessível ao público em geral.

Já na percepção de Trivisios (1987), o autor enfatiza-se que no processo de uma pesquisa qualitativa não é permitida as visões e percepções isoladas. Ela se desenvolve neste caso, por uma em interação dinâmica retroalimentando-se, reformulando-se constantemente.

Nesta perspectiva Godoy (1995), afirma que algumas características simples identificam os estudos definidos como "qualitativos". Segundo esta visão, um fenômeno ou ação pode ser compreendido no contexto em que ocorre e do qual é e faz parte, sendo necessário ser analisado numa perspectiva integrada.

Na concepção de Trivisios (1987), é necessário estabelecer a delimitação de técnicas, teorias e métodos que irão orientar a coleta e análise de dados, com a constante preocupação, com o propósito de manter um senso crítico dos dados coletados que resulta no teor na pesquisa.

Na visão de Vergara (1997), a pesquisa descritiva mostra as características de determinada população ou fenômeno, podendo estabelecer a relação entre variáveis e definir sua natureza. Não tem compromisso de explicar os fenômenos que descreve, embora sirva de base para tal explicação.

Chizzotti (2001) expõe que a pesquisa qualitativa se fundamenta em dados coligados nas interações interpessoais, na co-participação das situações dos informantes, analisadas a partir da significação que estes dão aos seus atos. 0 pesquisador participa, compreende e interpreta.

Andrade (1995), afirma que existem características básicas da pesquisa qualitativa, identificadas por alguns aspectos que são essenciais, sendo: descritiva; o ambiente e as pessoas nele inseridas não são reduzidos a variáveis, mas observados como um todo; o ambiente natural é a fonte direta dos conteúdos e o 
pesquisador é o instrumento fundamental; a preocupação do investigador está em relação ao envolvimento das pessoas, em que as mesmas dão a maioria das vezes suas vidas, porque utilizam o enfoque na análise das informações.

\section{Resultados e Discussão}

O presente estudo objetivou analisar por meio da literatura a cultura organizacional e sua relação com o desempenho das empresas.

A pesquisa também procurou apurar por quais elementos eram compostos a cultura e a relação da mesma com o comportamento organizacional, para que alcançasse a definição de uma cultura organizacional participativa e clara aos colaboradores, sob a influência de metas na empresa, recorrendo os estudos de Ferreira e Assmar, (2004) e outros.

Os autores descrevem que as empresas precisam encorajar seus funcionários a atingirem os objetivos estabelecidos, essa relação se faz por meio do conhecimento aplicado da cultura organizacional, pois quanto maior o entendimento da mesma, mais possibilidades de alcançar o lucro e melhor desempenho na organização.

Diante desta abordagem, procuraram-se bibliografias que constatassem fatores que confirmam a importância de observar a cultura organizacional, pelo fato de que, entende-la possibilita a visualização da ética aplicada na empresa e os valores estabelecidos, como também o nível de resistência a mudança de premissas ultrapassadas adotadas pelos funcionários.

Robbins (2005) definiu a cultura como o estudo organizacional que se faz importante, pois permite aos gestores, as vantagens de a princípio observarem como os valores da organização estão sendo absorvidos e de forma subsequente, ter a percepção da forma de como está a redução do nível de resistência a mudança, possibilitando assim aos mesmos, após a apresentação dos resultados, participarem de modo ativo na execução dos planos de ações.

A pesquisa também abordou como avaliar os colaboradores na organização com as culturas e observou-se que para realizar esta avaliação é necessário o foco em algumas dimensões coletivas da organização, pois para analisar o comportamento organizacional é necessário apresentar feedbacks constantes, desenho das etapas de trabalho, observar as políticas da empresa, grau de 
satisfação, motivação, atitudes, comprometimento e os sentimentos dos colaboradores, pois esses fatos influenciam no grau de desempenho dos funcionários e de metas da empresa.

\section{Conclusão}

O objetivo do presente artigo foi contextualizar a cultura organizacional como capacidade de exercer a influencia no comportamento de seus profissionais e gestores até a formulação de estratégias e o desempenho organizacional. Sendo assim, deve-se considerar a perspectiva de que o desempenho é um fenômeno sujeito a interferências e mudanças de inúmeras variáveis que interagem no processo.

Considera-se a cultura organizacional um dos elementos de grande validade, no qual compõe parte primordial para o bom desempenho do profissional e consequentemente, da organização. O estudo da cultura organizacional é importante, pois permite aos profissionais e gestores observarem de qual forma os valores da organização estão sendo estabelecidos e reconhecidos, visualizando a redução dos níveis de resistência à mudança.

Faz-se necessário, então, desenvolver planos de ações para melhorar o nível de desempenho, estimulando e despertando o interesse do empregado pela atividade, para que por meio da motivação possa aumentar a produtividade no desempenho de cada função, visto que, um dos fatores mais complexos são a subjetividade humana e particularidade de cada componente de um grupo.

Assim, conclui-se que as pesquisas aprofundadas sobre cultura e clima organizacional, são abordagens relevantes no âmbito das empresas, pois contribuem de forma importante, tanto para a academia, quanto para a prática mercadológica.

Por fim, sugere-se que a presente pesquisa tenha continuidade para complementação deste estudo e encontrar novos resultados revelados por esta. 


\section{Referências}

ANDRADE, J. Introdução à pesquisa qualitativa e suas possibilidades. RAE Revista de Administração de Empresas da Fundação Getúlio Vargas, São Paulo, vol. 35, n. 2, p. 57-63, 1995.

BARRETO, Leilianne M.T.S. et al. Cultura organizacional e liderança: uma relação possível? R. Adm., São Paulo, v. 48, n. 1, p. 34-52, 2013.

Brief, A. P. \& Weiss, H. M. (2002). Organizational behavior: affect in the workplace. Annual Review of Psychology. 53, 279-307.

Cautilli, J. \& Clarke, K. (2000). What does organizational behavior management have to offer social service organizations? In: OBM primer for aba'ers. Behavior Analyst Today, 1(1).

CHIAVENATO, Idalberto. Gestão de pessoas: e o novo papel dos recursos humanos nas organizações. 2.ed. Rio de Janeiro: Elsevier, 2004

CHIAVENATO, Idalberto. Gestão de pessoas: o novo papal dos recursos humanos nas organizações. 3. ed. Rio de Janeiro: Campus, 2010.

CHIZZOTTI, Antônio. Pesquisa em ciências humanas e sociais. 5. ed. São Paulo: Cortez, 2001.

Cummings, L. L. (1982). Organizational behavior annual review of psychology. 33, pp. 541-579.

FLEURY, M. T.; FISCHER, R. M. Cultura e poder nas organizações. São Paulo: Atlas, 1989.

Glenn, S. S., \&Malott, M. E. (2004). Complexity and selection: implications for organizational change. Behaviorand Social Issues, 13, pp. 89-106.

GODOY, A. S. Introduçãoà pesquisa qualitativa e suas possibilidades. Revista de Administração de Empresas. São Paulo, v.35, n.2, p.57-63, mar/abr de 1995a.

HALL, R. H. Organizações: estruturas e processos. Rio de Janeiro: PrenticeHall do Brasil, 1978.

JOHANN, Sílvio Luiz. Gestão da cultura corporativa: como as organizações de alto desempenho gerenciam sua cultura organizacional. São Paulo: Saraiva, 2004.

LACOMBE, F. J. M; HEILBORN, G. L. J. Administração: princípios e tendências. São Paulo: Sarai-va, 2003.

LUZ, Ricardo. Gestão do Clima Organizacional. Rio de Janeiro: Qualitymark, 2003.

MAXIMIANO, Antônio Cesar Amaru. Teoria geral da administração: da revolução urbana à revolução digital. 5. ed. São Paulo: Atlas, 2005.

Mitchell, T. R. (1979). Organizational Behavior. Annual Review of Psychology. 30, 243-281.

MORGAN, Gareth. Imagens da organização: edição executiva. São Paulo: Atlas, 2009. 
Morgan, M., \&Smircich, L. (1980). The case for qualitative research. Academyof Management Review, 5(4), 491-500.

NEWSTROM, John W. Comportamento Organizacional: o comportamento humano no trabalho. São Paulo: McGraw-Hill, 2008.

PIRES, José Calixto de Souza; MACÊDO, Kátia Barbosa. Cultura organizacional em organizações públicas no Brasil. Revista de Administração Pública. Rio de Janeiro, 2006. Disponível em: Acessado em 13/06/2011

Redmon, W. K. \& Wilk, L. A. (1991). Organizational behavioral analysis in the United States: public sector organizations. In P. A. Lamal (Ed.). Behavioral analysis of societies and cultural practices. (pp. 107-123). New York: Hemisphere Publishing Corporation.

ROBBINS, Stephen P.Comportamentoorganizacional. São Paulo: Pearson Prentice Hall, 2005.

ROBBINS, Stephen. Comportamento Organizacional. São Paulo: Prentice Hall, 2010.

SCHEIN, Edgar H. Coming to a New Awareness of Organizational Culture. Sloan Management Review Winter - Massachusetts Institute of Tecnology.

SCHEIN, Edgar. Organizational Culture and Leadership. San Francisco, Jossey Bass Publications. 2 ${ }^{\mathrm{a}}$ Ed. 1989.

Siqueira, M. M. M. (2002). Medidas do comportamento organizacional. Estudos de Psicologia. 7 (número especial), 11-18.

SALOMAO, P. E. A. et al. As Tecnologias de Informação e Comunicação (TIC) no ensino superior. Revista Multidisciplinar do Nordeste Mineiro, v. 1, 2018.

TAMAYO, Alvaro.Cultura e saúde nas organizações. In: FERREIRA, Maria Cristina; ASSMAR, Eveline Leal. Cultura, Satisfação e Saúde nas Organizações. Porto Alegre: Artmed, 2004.

TRIVISIOS, Augusto Nibaldo da S. Introdução à pesquisa emciênciassociais: a pesquisa qualitativa em educação. São Paulo: Atlas, 1987.

VERGARA, Sylvia Constant. Projeto e relatórios de pesquisa em administração. São Paulo: Atlas, 1997.

VERGARA, Sylvia Constant. Projetos e relatórios de pesquisa em administração. 7 . ed. São Paulo: Atlas, 2006.

ZANELLI, José Carlos; BORGES-ANDRADE, Jairo Eduardo; BASTOS, Antonio Virgílio Bittencourt. Psicologia, organizações e trabalho no Brasil. In: SILVA, Narbal; ZANELLI, José Carlos. Cultura Organizacional. Porto Alegre: Artmed, 2004. 